\title{
Simulation of Nitride Semiconductor MOVPE
}

Kazuhiro Ohkawa

Electrical Engineering program, King Abdullah University of Science and Technology (KAUST), Thuwal, Saudi Arabia

\begin{abstract}
This article seeks to help readers understand the MOVPE growth of nitride semiconductors as a part of science. MOVPE is the abbreviation for metalorganic vapor-phase epitaxy. Therefore, the precursors used are metalorganic gases and ammonia. The precursors decompose or react with others in the gas phase. The obtained reactive molecules form semiconductor layers on substrates. Those growth reaction pathways and the polymer formation will be discussed numerically for GaN, InN, InGaN, AIN, and AIGaN in this article. For those materials, the numerical analyses of growth rate and alloy composition exhibited the qualitative and quantitative agreements with experiments. The reader can see the growth mechanism, and experts will understand the current MOVPE conditions of nitride semiconductors.
\end{abstract}

Keywords: Nitride Semiconductors, MOVPE, Simulation, GaN, AlGaN, InGaN

1. Introduction

2. Simulation and experiment

3. GaN-MOVPE

4. InN- \& InGaN-MOVPE and high-In-content InGaN LEDs

5. AIN-MOVPE

6. AIGaN-MOVPE and polymer formation

7. Summary

8. Outlook

Appendix

References

\section{Introduction}

Nitride semiconductors such as GaN, AIN, InN, and their alloys are useful in efficient optical devices and electronic devices. Those devices consist of thin-film structures. Metalorganic vaporphase epitaxy (MOVPE) and molecular beam epitaxy (MBE) are widely used to grow those thin films including nitride semiconductors on research bases. However, most industries adopt MOVPE because of its productivity. The merits of MOVPE are:

- continuous growth cycles by precursor supply,

- tunable growth rate and alloy composition by gas flows,

- fabrication of heterostructures such as superlattices (SLS) and a pn junction, and

- homogeneous growth in multiple wafers. 
Those merits support the mass-production of nitride semiconductor device structures.

MOVPE growth conditions for nitride semiconductors are different from those of other semiconductors such as arsenides and phosphides. In the cases of arsenide or phosphide semiconductor devices, the whole structure consisting of several binary or ternary semiconductor alloys is grown at a constant temperature and constant pressure [1-3]. In contrast, the optimal growth conditions for GaN, AIN, InN, AIGaN, and InGaN are different in terms of temperature, pressure, V/III ratio (initial mole fraction ratio of $\mathrm{NH}_{3}$ to total group-III precursors), and so on. Therefore, multiple heterostructures such as nitride light-emitting diodes (LEDs) and nitride laser diodes (LDs) have unique growth profiles using various values in terms of temperature, pressure, and other parameters [4-6]. Those optimizations have been done through experiments. This is a rule of thumb. Simulation results will reveal possible mechanisms underlying nitride MOVPE.

This article will show MOVPE simulation in GaN [7], InGaN [8], AIN [9], and AIGaN [10]. The article will explain each growth mechanism and its comparison. That scientific insight will provide some hints to experts in this field about modifying an MOVPE reactor or optimizing the growth conditions efficiently. MOVPE growth includes many numbers of gas-phase and surface chemical reactions. The key point of the simulation is to understand the mechanisms that have enormous implications for MOVPE growth.

In addition, because the chemical reaction rate significantly depends on temperature, the temperature distribution in an MOVPE reactor is crucial. It is possible to calculate the temperature distribution in an MOVPE reactor using the temperature-dependent thermal parameters [11]. Here, the author will focus on chemical reactions in nitride MOVPE. If readers want to know the temperature part, I recommend reading reference 11 . Chemical reactions have a style of the Arrhenius expression, and each molecule has weight, potential, fluid, and thermal parameters. The concrete values of the reaction and molecular parameters are available in the nitride-MOVPE database (Wavefront, Japan) [12]. This database is based on previous works [7-11].

\section{Simulation and experiment}

Experimental data were obtained from samples grown by a single-wafer horizontal MOVPE reactor (Taiyo-Nippon Sanso, Japan). The flow-channel was made of quartz. The height of the flow channel inside was $7.5 \mathrm{~mm}$ or $5.0 \mathrm{~mm}$. Precursors were trimethyl-gallium ( $\mathrm{TMGa}$; $\mathrm{Ga}\left(\mathrm{CH}_{3}\right)_{3}$ ), trimethylindium ( $\mathrm{TMIn}$; In $\left.\left(\mathrm{CH}_{3}\right)_{3}\right)$, trimethyl-aluminum (TMAl; Al $\left.\left(\mathrm{CH}_{3}\right)_{3}\right)$, ammonia $\left(\mathrm{NH}_{3}\right)$, $\mathrm{H}_{2}$-diluted silane $\left(\mathrm{SiH}_{4}\right)$, and bis-cyclopentadienyl-magnesium $\left(\mathrm{Cp}_{2} \mathrm{Mg}\right)$. The carrier gas was hydrogen $\left(\mathrm{H}_{2}\right)$ and/or nitrogen $\left(\mathrm{N}_{2}\right)$. Substrates were 2-inch c-plane sapphire wafers. The typical GaN growth temperature was $1030^{\circ} \mathrm{C}$. The growth temperatures were calibrated by melting points of metals on the substrate surface. The value of growth temperature hereafter is that at the center of a substrate because the MOVPE machine has a temperature distribution such that the last $5-\mathrm{mm}$ edge area is a little cooler. A substrate/quartz tray/SiC-coated carbon susceptor could rotate together, but it was not rotated to be compared with computational results.

MOVPE simulation of GaN, InGaN, AIN, and AIGaN will be discussed in the following chapters using computational fluid dynamics (CFD) hereafter. The used code is CFD-ACE+ (ESI, France) [13] with the nitride-MOVPE database (Wavefront, Japan) [12]. The nitride-MOVPE database includes the reaction parameters for each modified Arrhenius equation, the molecular parameters such as Lennard Jones parameters, Sutherland's law coefficients, specific heat coefficients, and the high-temperature material parameters such as the optical absorption coefficient spectra and the specific heats. The 
modified Arrhenius equations for the gas-phase and surface reactions express chemical rate constants $k: k=A T^{n} \exp (-E / R T)$. Notations of $A, T, E$, and $R$ are the frequency factor, temperature, activation energy, and gas constant, respectively. Those $A$ and $E$ were evaluated by thermodynamics such as the collision and transition-state theories. The CFD code employs the finite volume method to solve basic fluid equations of mass, momentum, energy, and species conservation laws in a stationary state. Also, the other recent codes will be available as far as the chemical reactions and thermal radiation and conduct in the nitride-MOVPE database can be considered. Chemical reactions are quite dependent on temperature. Intense thermal radiation is observable at the growth temperatures of nitride semiconductors by MOVPE. It is important to consider the thermal radiation and absorption of materials in the MOVPE reactor to accurately determine the temperature distribution in the simulation [11, 12]. These optical properties, the thermal conductivity, and the heat capacity of both quartz and sapphire were taken into account in the simulations. Also, there are thin spaces among a substrate, a tray, and a susceptor. The low thermal conductivity of the thin space was calculated by using Thin Wall in the CFD-ACE+ considering the gas in the space and the thermal radiation.

\section{GaN-MOVPE}

GaN-MOVPE is the basis of nitride semiconductor growth. The precursors are $\mathrm{TMGa}$ and $\mathrm{NH}_{3}$, and the carrier gas is $\mathrm{H}_{2}$ or $\mathrm{N}_{2}$ or their mixture. The typical growth temperature of $\mathrm{GaN}$ is around $1000^{\circ} \mathrm{C}$. Such high temperatures can cause decomposition of the precursors as shown in Figure 1 [14-17]. The simulation of this idea was in good agreement with the experimental GaAs growth-rate distribution on a substrate [14]. However, in the case of $\mathrm{TMGa}+\mathrm{NH}_{3}$, while the idea could explain a massspectroscopic observation [15], it could not account for GaN growth itself. This suggests that the mechanism of GaN-MOVPE seems to be more complicated.

The activation energies of every step in the thermal decomposition process depend on atmospheres. In the case of the hydrogen atmosphere, $\mathrm{H}$ atoms decomposed from $\mathrm{H}_{2}$ and assist in the TMGa decomposition by emitting $\mathrm{CH}_{4}$ molecules (TMGa $+\mathrm{H} \rightarrow \mathrm{DMGa}+\mathrm{CH}_{4}$ ) [16]. On the other hand, the nitrogen atmosphere does not assist in creating $\mathrm{CH}_{4}$ molecules. Therefore, the TMGa molecule decomposes into smaller molecules by emitting the $\mathrm{CH}_{3}$ group (TMGa $\rightarrow$ DMGa $+\mathrm{CH}_{3}$ ) with higher activation energies rather than those at the hydrogen atmosphere by 6 times [14, 16]. The different atmospheres are adopted for the growth of different nitride semiconductors. For example, the hydrogen atmosphere is general for the growth of GaN, AIN, and AIGaN, but the InGaN growth adopts the nitrogen atmosphere.

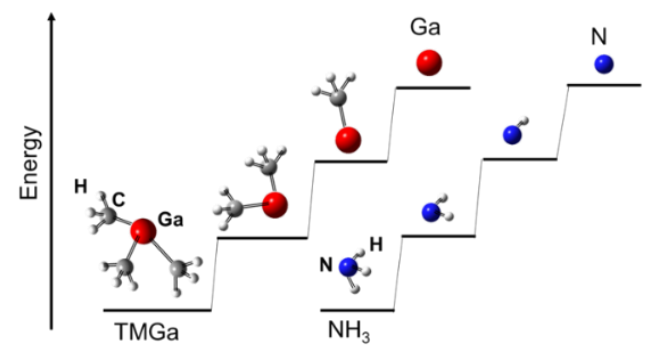

Figure 1 Pyrolysis of precursors in MOVPE growth of GaN. Each transition energy depends on assisting molecules or radicals. 


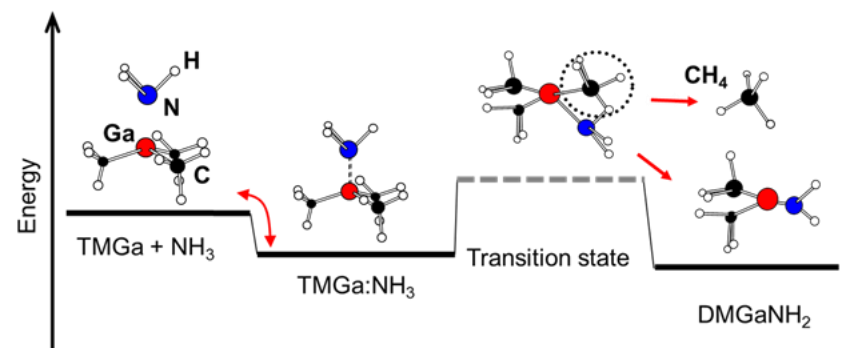

Figure 2 Formation of TMGa: $\mathrm{NH}_{3}$ adducts and its first pyrolysis.

Precursors to $\mathrm{TMGa}$ and $\mathrm{NH}_{3}$ flow simultaneously except for the flow-rate modulation [18] in MOVPE growth. A TMGa molecule and an $\mathrm{NH}_{3}$ molecule react to each other and form a TMGa: $\mathrm{NH}_{3}$ adduct, and the adducts decompose thermally [19-21]. A Ga atom in TMGa and an $\mathrm{N}$ atom in $\mathrm{NH}_{3}$ have a coordinate bond in the TMGa: $\mathrm{NH}_{3}$ adduct. The coordinate bond changes to a covalent bond after emitting a $\mathrm{CH}_{4}$ molecule from the adduct. More $\mathrm{CH}_{4}$ emissions are possible, and result in smaller molecules of $\left(\mathrm{CH}_{3}\right)_{2} \mathrm{Ga}_{\mathrm{NH}} \mathrm{NH}_{2}$ (DMGaNH 2 , here DM is dimethyl), MMGaNH (MM is monomethyl), and Ga$\mathrm{N}$, sequentially. Because the smaller molecules have more dangling bonds, their reactivity becomes higher. Those reactive molecules are generated at a certain temperature because the decomposition is based on thermal energy. The substrate surface will be the hottest area in the reactor. Therefore, the most reactive molecules will be deposited on the substrate. If those molecules could not reach the substrate surface, they will react to each other, resulting in polymerization.

There are two points in crystal growth by MOVPE. The first point is the chemical reaction, and the second is mass transport. Chemical reactions and mass transport are sensitive to temperature and gas flow. Here, the chemical reactions are studied mainly because any code of fluid dynamics includes mass transport. Figure 3 shows most of the possible chemical reactions in GaN-MOVPE using a $\mathrm{TMGa} / \mathrm{NH}_{3} / \mathrm{H}_{2} / \mathrm{N}_{2}$ system [7]. Those reaction pathways include pyrolysis of $\mathrm{TMGa}$ and $\mathrm{NH}_{3}, \mathrm{TMGa}: \mathrm{NH}_{3}$ adduct pyrolysis, and polymer formation. The GaN-MOVPE simulation contains 70 reactions in the gas phase and 27 reactions on the surface [12].

The lowest temperature region in a reactor is the gas inlet at room temperature, and the highest temperature region is around a heated substrate. A sharp temperature gradient exists around the substrate. As chemical reactions are sensitive to temperature, the temperature gradient will generate certain molecules at a certain temperature. If those generated molecules were reactive, they would polymerize, such as $\left[\mathrm{DMGaNH}_{2}\right]_{\mathrm{n}},[\mathrm{MMGaNH}]_{\mathrm{n}}$, and $[\mathrm{Ga}-\mathrm{N}]_{\mathrm{n}}$, as shown in Figure 3 . The value of $\mathrm{n}$ is limited to 3 or 6 in this model to save on the calculation time for each simulation. Further polymerization $(n>6)$ will presumably happen in the real MOVPE. Therefore, the concentration of a polymer with the largest $n$ values will include the larger polymers $(n>6)$ in an experiment. 


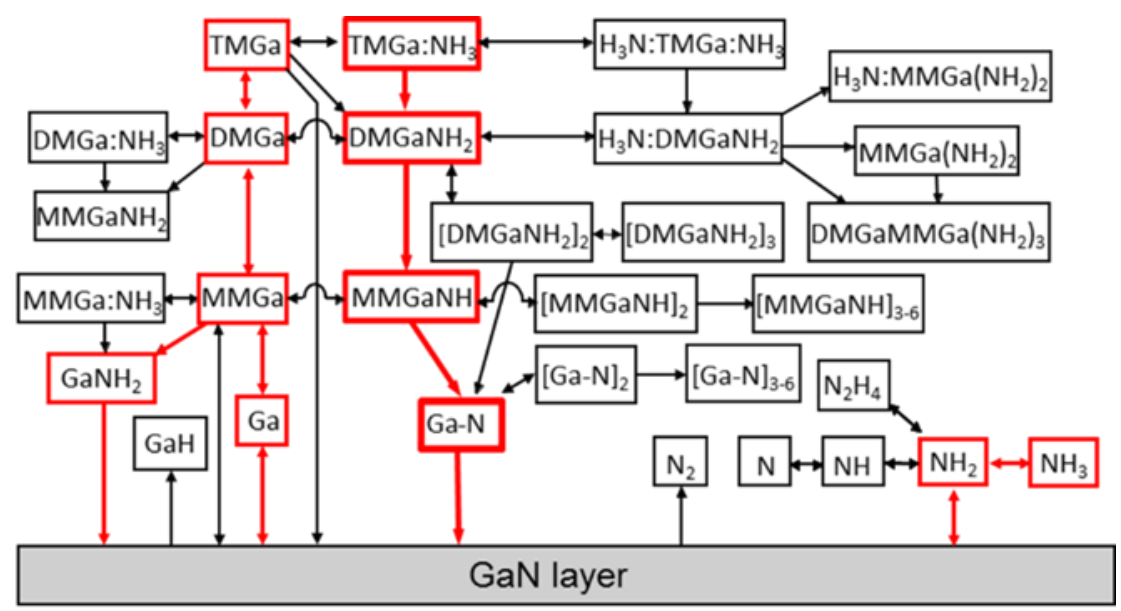

Figure 3 Schematic diagram of representative reaction pathways for the MOVPE growth of $\mathrm{GaN}$ from the $\mathrm{TMGa} / \mathrm{NH}_{3} / \mathrm{H}_{2} / \mathrm{N}_{2}$ system [7]. The thick red frames and arrows indicate the main growth path of the $\mathrm{TMGa}_{\mathrm{NH}}$ adduct pyrolysis. The second thick ones are the second growth paths of the TMGa and $\mathrm{NH}_{3}$ pyrolysis. $\mathrm{TM}$, $\mathrm{DM}$, and $\mathrm{MM}$ indicate trimethyl $\left(\mathrm{CH}_{3}\right)_{3^{-}}$, dimethyl $\left(\mathrm{CH}_{3}\right)_{2^{-}}$, and monomethyl $\mathrm{CH}_{3^{-}}$, respectively.

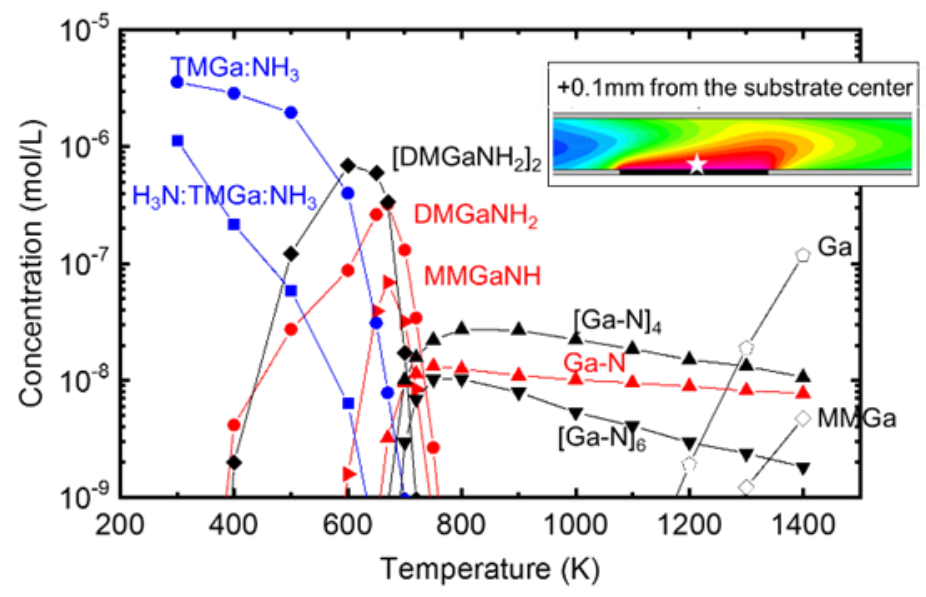

Figure 4 Concentrations of representative Ga-containing molecules vs. susceptor temperature during the MOVPE growth of GaN [7]. The concentrations are from the gas phase at $+0.1 \mathrm{~mm}$ from the substrate center.

The temperature dependence of the chemical states is shown in Figure 4. The concentrations of some Ga-containing intermediates came from those at the position $0.1 \mathrm{~mm}$ above the substrate center. The different species and their concentrations reflect decomposition or reactions of the intermediates, which can be categorized into four regimes in terms of temperature: (1) the temperature range lower than $400 \mathrm{~K}$ is the adducts' regime, (2) in the temperature range of 400-750 $\mathrm{K}$, those adducts, one by one, change into reactive molecules due to $\mathrm{CH}_{4}$ elimination. (3) In the temperature range of 750-1200 K, Ga-N molecules become the major species, and (4) at temperatures higher than $1200 \mathrm{~K}$, the sublimation of the GaN crystal starts. 
The first $\mathrm{CH}_{4}$ elimination from a TMGa: $\mathrm{NH}_{3}$ adduct happens at $400 \mathrm{~K}$. DMGaNH 2 molecules are generated as shown in Figure 4, followed by the formation of [DMGaNH$]_{2}$ and $[\mathrm{DMGaNH}]_{3}$ polymers. The concentration of the $\left[\mathrm{DMGaNH}_{2}\right]_{2}$ polymers showed a similar temperature-dependence to that of the $\mathrm{DMGaNH}_{2}$ molecule. The [DMGaNH$]_{3}$ polymers had been considered to be responsible for $\mathrm{GaN}$ growth [22]. In this simulation, the concentration of [DMGaNH$\left.]_{3}\right]_{3}$ around the substrate surface was as low as $10^{-16}-10^{-11} \mathrm{~mol} / \mathrm{L}$ at $700-1400 \mathrm{~K}$. Such a concentration of [DMGaNH$]_{3}$ is too low to contribute to $\mathrm{GaN}$ growth. The main reason is the consideration of reactions $\mathrm{DMGaNH}_{2} \rightarrow \mathrm{MMGaNH}+\mathrm{CH}_{4}$, and $\mathrm{MMGaNH} \rightarrow \mathrm{Ga}-\mathrm{N}+\mathrm{CH}_{4}$. The reaction pathways in this article include these reactions reported by Timoshkin et al. [23]. The second $\mathrm{CH}_{4}$ emission occurs at $600 \mathrm{~K}$; thus, $\mathrm{DMGaNH} \mathrm{H}_{2}$ molecules become MMGaNH radicals. The last $\mathrm{CH}_{4}$ dissociates at $650 \mathrm{~K}$, producing $\mathrm{Ga}-\mathrm{N}$ molecules. $\mathrm{Ga}-\mathrm{N}$ molecules will subsequently react with surface sites as $\mathrm{GaN}$ growth. At temperatures higher than $1200 \mathrm{~K}$, Ga atoms and MMGa could be seen. These originated not from TMGa pyrolysis but from the sublimation of the GaN crystal.

Temperatures around a substrate in a reactor are shown in Figure 5 (b). The upper wall was heated by the thermal radiation from the substrate and the susceptor. The maximum temperature of the upper wall was about $890 \mathrm{~K}$. The bottom wall was heated mainly by the thermal conduction from the susceptor and hot gas at the downstream side. The GaN growth took place not only on a substrate but also on the reactor walls, and no growth was set on the bare susceptor surface in the simulation. The growth rate of the GaN layer on the reactor walls and the substrate are shown in Figures 5 (a) and (c). The GaN growth took place at $9-25 \mathrm{~cm}$ of both upper- and bottom-wall surfaces. Those wall areas heated above $600 \mathrm{~K}$ and many Ga-N molecules would be generated. It is found that Ga-N molecules contribute to the growth of a GaN layer. Some growth experts know of such GaN deposition on the reactor walls through their experiments.

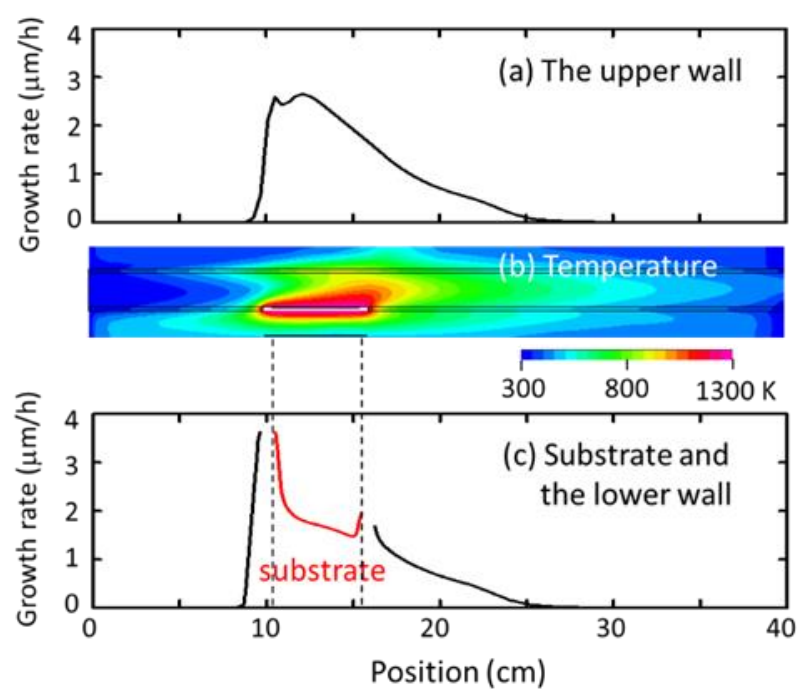

Figure $5 \mathrm{GaN}$ growth rate distributions of (a) the upper wall of a flow channel, (c) the substrate area, and the lower wall [24]. (b) temperature distribution of the horizontal reactor with the susceptor at $1300 \mathrm{~K}$.

Temperature dependences of GaN growth rates in the experiment and simulation are compared in Figure 6. There are three regimes in growth rates. The first regime is temperatures below $700 \mathrm{~K}$, the 
second is temperatures from 700-1300 K, and the third is temperatures over $1300 \mathrm{~K}$. At temperatures below $700 \mathrm{~K}$, the simulation results are in agreement with the experimental data. The lowtemperature range indicates that the rate-determining step is the reaction limit. Thus, the growth rate is very sensitive to temperature in this region. The growth rates saturate in the middle-temperature range of $700-1300 \mathrm{~K}$. The region is the mass transport limit. This means, for example, that $50 \%$ more precursors cause a $50 \%$ higher growth rate. The experimental values in this range are close to the simulation with the formation of [Ga-N $]_{n}$ polymers rather than that without such polymer formation. The consideration of the Ga-N polymerization (Ga-N $\rightarrow[\mathrm{Ga}-\mathrm{N}]_{2-6}$ ) is crucial in the GaN-MOVPE. This indicates that Ga-N molecules contribute to GaN-MOVPE growth. The last regime over $1300 \mathrm{~K}$ exhibits some decreases in growth rates. This means that the sublimation of the GaN layer is not negligible. This idea is a good match with the phenomena shown in Figure 4. It shows the evaporation of Ga atoms and MMGa molecules above $1200 \mathrm{~K}$. Typical GaN growth temperatures are $1030^{\circ} \mathrm{C}(1300 \mathrm{~K})$ and $550^{\circ} \mathrm{C}(820 \mathrm{~K})$ for high-quality $\mathrm{GaN}$ and low-temperature GaN buffer layers, respectively. In both cases, Figure 4 shows that the major reactive molecules are $\mathrm{Ga}-\mathrm{N}$ molecules.

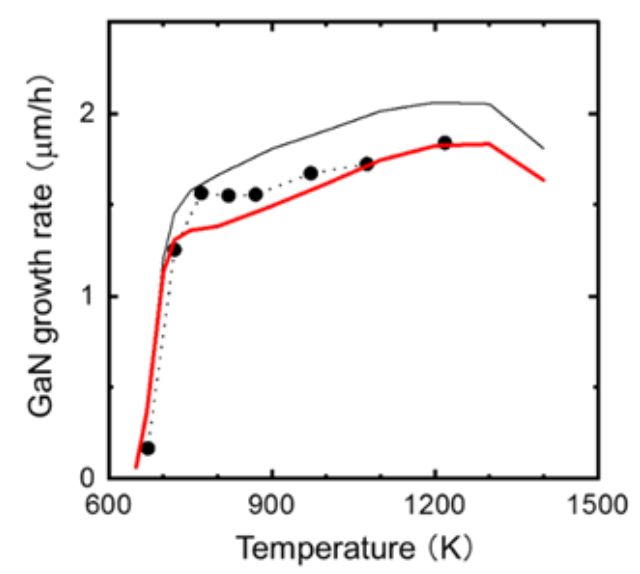

Figure 6 Simulated and experimental GaN growth rates as functions of temperature [25]. The thick red line is the simulation considering the formation of $[\mathrm{Ga}-\mathrm{N}]_{\mathrm{n}}$ polymers. The black line did not include such polymer formation. The solid circles are experimental values.

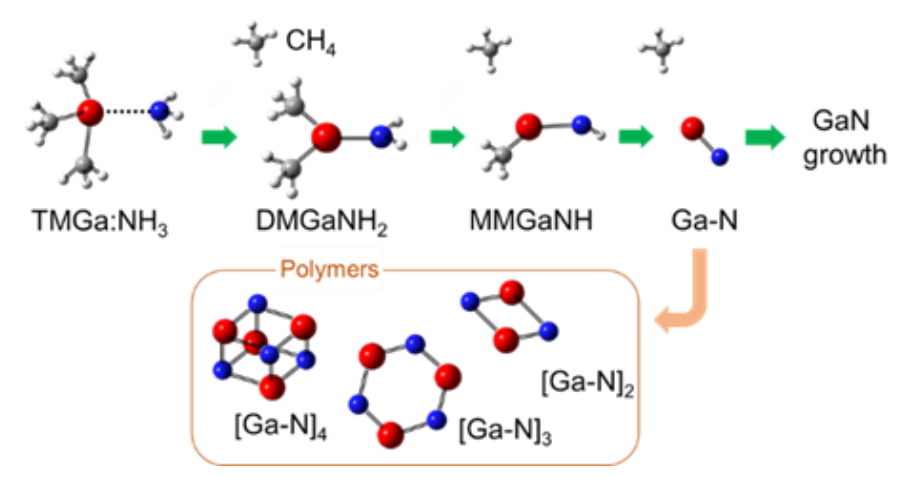

Figure 7 The main growth process in the atmospheric MOVPE growth of GaN from TMGa: $\mathrm{NH}_{3}$ adducts at $1300 \mathrm{~K}$. Only [Ga-N]n polymers were shown here. 
Figure 7 shows the main reaction pathway of GaN-MOVPE. The consideration of polymer formations of $\left[\mathrm{DMGaNH}_{2}\right]_{n},[\mathrm{MMGaNH}]_{n}$, and $[\mathrm{Ga}-\mathrm{N}]_{\mathrm{n}}$ was mandatory to realize the quantitative agreement with the experimental growth rate. The contribution of Ga-N molecules to the growth rate was $90 \%$ under the atmospheric MOVPE. The $10 \%$ contribution is the precursors' pyrolysis that is shown as the minor growth pathway in Figure 3. Also, the contributions of $\mathrm{Ga}-\mathrm{N}$ molecules and the precursors' pyrolysis on growth rate change with growth pressure. The contribution of Ga-N molecules on growth decreases to around $60 \%$ at $10 \mathrm{kPa}$. Low pressure prevents the collision of molecules; therefore, the TMGa: $\mathrm{NH}_{3}$ adduct formation is suppressed.

\section{InN- \& InGaN-MOVPE and high-In-content InGaN LEDs}

The bandgap of InGaN varies from 0.67 to $3.42 \mathrm{eV}[26,27]$ depending on indium content. InGaN with any In content can keep the wurtzite structure. As InGaN is the active region material for LEDs and LDs, InGaN devices cover ultraviolet (UV) to infrared (IR) including the whole visible region. Not only blue LEDs, but also violet, green, yellow, and red LEDs, are made of InGaN as the active region [4, $5,28]$. InGaN-based LED structures have larger band-offsets in the conduction and valence bands between QWs and claddings compared to those of InGaP-based LED structures. Therefore, InGaNbased red LEDs exhibit a good characteristic temperature as high as $399 \mathrm{~K}$ [29]. The unique point of InGaN-MOVPE is the nitrogen atmosphere during its growth. The hydrogen atmosphere is general for the MOVPE growth of GaN, AIN, and AIGaN. However, indium atoms are not incorporated into the nitride materials under the $\mathrm{H}_{2}$ atmosphere because the hydrogen etching is efficient for InN and InGaN. Therefore, the nitrogen atmosphere is usually used for InGaN-MOVPE.

The modeling of representative reaction pathways in a $T M I n / \mathrm{NH}_{3} / \mathrm{H}_{2} / \mathrm{N}_{2}$ system is shown in Figure 8. There are mainly three kinds of reaction groups: pyrolysis of precursors, pyrolysis of adducts, and polymer formations. Compared to GaN-MOVPE, the pyrolysis of precursors is major, while the pyrolysis of adducts and the polymer formations are suppressed in the InN-MOVPE. The $\mathrm{NH}_{2}$ molecules decomposed from ammonia and In atoms from TMIn are the main path (100\%) to the InN growth, eventually. The InGaN-MOVPE simulation was in quantitative agreement with the experiment. The simulation considers the following three points: (1) the chemical reactions among TMGa and TMIn are negligible, which means that the simple plus of reactions in the $\mathrm{TMGa} / \mathrm{NH}_{3} / \mathrm{H}_{2} / \mathrm{N}_{2}$ system and those in the TMIn/ $/ \mathrm{NH}_{3} / \mathrm{H}_{2} / \mathrm{N}_{2}$ system are valid for InGaN-MOVPE simulation, (2) the re-evaporation of $\mathrm{Ga}$ and In atoms from the surface is included, and (3) hydrogen etching of $\mathrm{GaN}$ and $\mathrm{InN}$ is considered.

Figure 9 shows temperature dependencies of the InGaN growth rate and In content in experiments and simulations. The simulation contains gas-phase and surface reactions and their molecular parameters [12]. Two variations of the simulation were carried out, i.e., with and without re-evaporation of In atoms adsorbed on the growth surface. Considering the In re-evaporation, the simulation exhibited strong temperature dependences of growth rate and In content, and it indicated good agreement with the experiments. It is found that growth temperature strongly influences In reevaporation from InGaN. There are some differences in InGaN growth rates between experiments and the thick red simulations at $671^{\circ} \mathrm{C}$ and $717^{\circ} \mathrm{C}$. Because InGaN layers grown at those low temperatures became porous, those experimental growth rates were overestimated. The effective growth rates presumably could be in good agreement. 


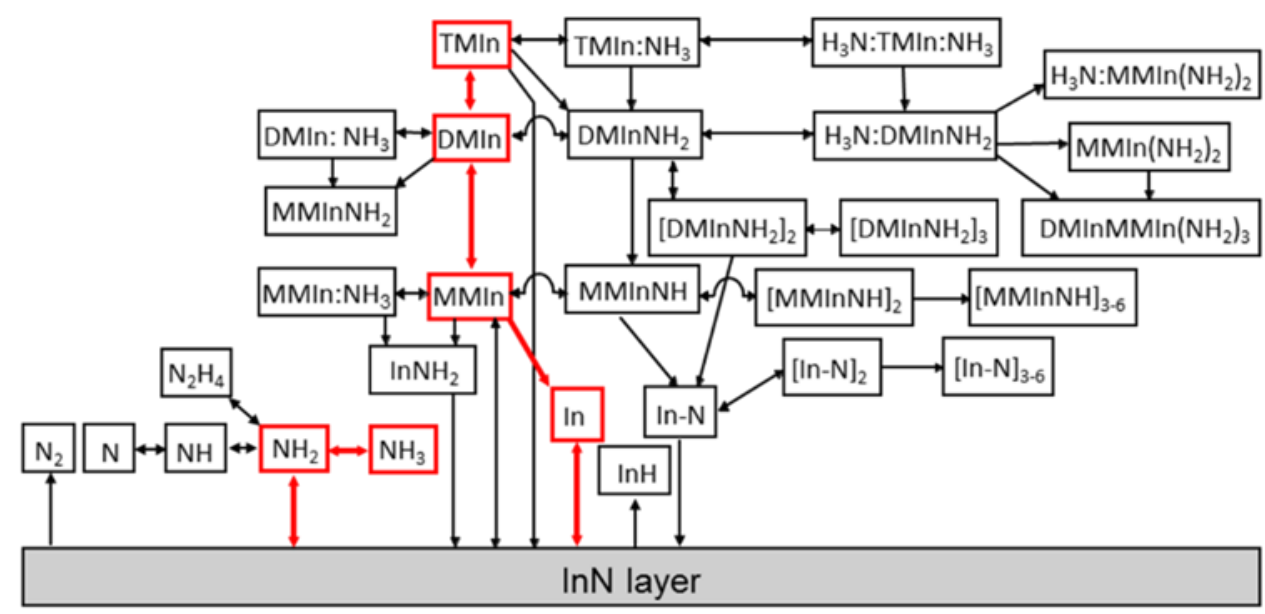

Figure 8 Schematic diagram of representative reaction pathways for the MOVPE growth of $\operatorname{InN}$ from the TMIn/ $/ \mathrm{NH}_{3} / \mathrm{N}_{2}$ system [8]. The thick red frames and arrows indicate the main growth paths of the TMIn \& $\mathrm{NH}_{3}$ pyrolysis. $\mathrm{TM}, \mathrm{DM}$, and $\mathrm{MM}$ indicate trimethyl $\left(\mathrm{CH}_{3}\right)_{3^{-}}$, dimethyl $\left(\mathrm{CH}_{3}\right)_{2^{-}}$, and monomethyl $\mathrm{CH}_{3^{-}}$, respectively.

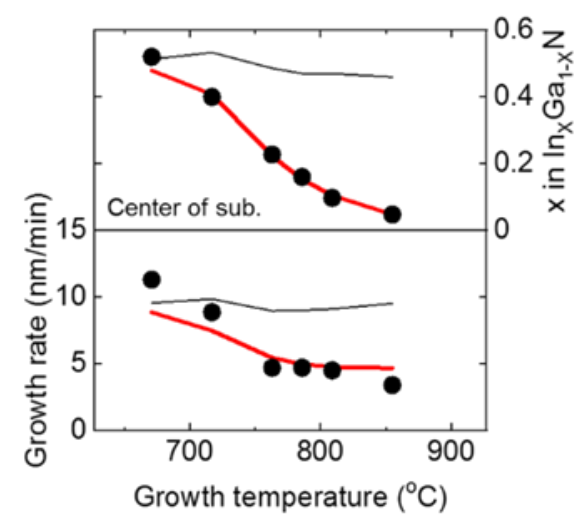

Figure 9 Temperature dependences of growth rate and In content in InGaN [8]. The thick red and thin black curves are simulations with or without indium reevaporation during growth, respectively. The solid circles are experimental values.

Simulation can cut any reaction paths. Therefore, it is possible to confirm the contribution of each reaction path to In content in InGaN. The cut of the adsorption of In or $\mathrm{NH}_{2}$ on the surface caused "zero"-In-content in InGaN. This means that the increments of In and $\mathrm{NH}_{2}$ concentrations on the surface can increase In content in InGaN. Two kinds of flow channels were used. One flow channel has a $7.5 \mathrm{~mm}$ height inside. The $7.5 \mathrm{~mm}$ height flow channel is named "conventional" because the conventional flow channel can grow InGaN with the same trend as other institutes, which will be shown in Figure 11. Another is the so-called micro-flow channel, which has a $5.0 \mathrm{~mm}$ height. Despite the existence of the same flow and temperature conditions (TMGa=11.2 $\mu \mathrm{mol} / \mathrm{min}, \mathrm{TMIn}=43.4$ $\mu \mathrm{mol} / \mathrm{min}, \mathrm{NH}_{3}=4.5 \mathrm{slm}$ (standard liter per minute), $\mathrm{N}_{2}=10.6 \mathrm{slm}$, growth temperature $=785^{\circ} \mathrm{C}$ ), the spatial distributions of $\mathrm{In}$ atoms and $\mathrm{NH}_{2}$ molecules are different in those flow channels in the simulation shown in Figure 10. Both In and $\mathrm{NH}_{2}$ concentrations in the micro-flow channel are much higher than those in the conventional one by $27 \%$ and $20 \%$ on the substrate surface, respectively [8]. In experiments, the In contents of InGaN layers grown using the micro and conventional flow channels were $29 \%$ and $14 \%$, respectively [8]. 
(a) In atom concentration (Max : $0.13 \mu \mathrm{mol} / \mathrm{L}$ )

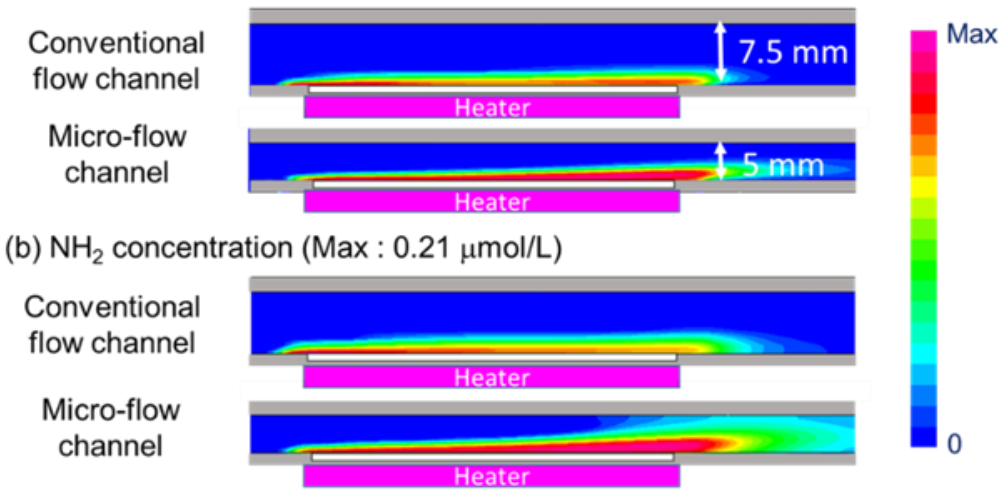

Figure 10 Concentration distributions of (a) In atoms decomposed from TMIn and (b) $\mathrm{NH}_{2}$ molecules from $\mathrm{NH}_{3}$ in conventional and micro-flow channels. The amounts of precursors are identical in both flow channels.

The growth of high-In-content in InGaN would originate from the high concentrations of In atoms and $\mathrm{NH}_{2}$ molecules on the growth surface. If the In content is a certain amount, the micro-flow channel has the potential to raise the InGaN growth temperature compared to the conventional one. Figure 11 shows the dependence of the electroluminescence (EL) peak wavelength from InGaN on the growth temperature of the InGaN layers using the conventional or micro-flow channels. The relationship between the EL peak wavelength and growth temperature with InGaN LEDs grown by the conventional flow channel has the same trend as those in previous studies [31, 32]. This universal trend indicates that the mechanism of In-incorporation is identical in all of these cases. Therefore, the indium content of InGaN is generally determined only by the growth temperature rather than the types of reactors. However, the micro-flow channel is unique. That can raise the growth temperature. The EL peak wavelength at $600 \mathrm{~nm}$ is grown at the growth temperatures of $710^{\circ} \mathrm{C}$ and $760^{\circ} \mathrm{C}$ for the conventional and micro-flow channels, respectively. That temperature difference of $50^{\circ} \mathrm{C}$ can be explained by high In and $\mathrm{NH}_{2}$ concentrations on the growth surface in the case of the micro-flow channel. Higher growth temperatures realize a higher quality of InGaN in the same In content. Therefore, InGaN grown by the micro-flow channel shows higher internal quantum efficiency in the high-In-content region [8].

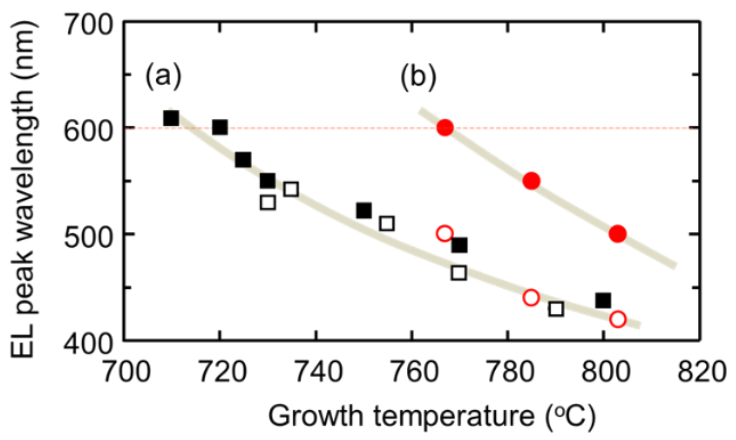

Figure 11 Dependence of the EL peak wavelength from InGaN LEDs on the InGaN growth temperature [30]. (a) Conventional and (b) micro-flow channels were used. The red open and solid circles represent the data from the author's group. The solid and open squares are data from LEDs in References 31 and 32, respectively. Every current for the LED operation was DC $20 \mathrm{~mA}$. The red broken line indicates a 600 nm wavelength. 


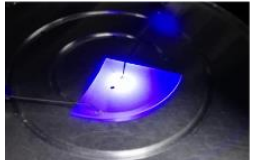

$\lambda_{\mathrm{p}}=425 \mathrm{~nm}$

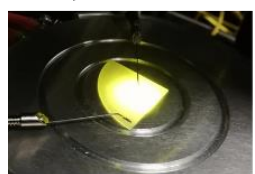

$\lambda_{\mathrm{p}}=580 \mathrm{~nm}$

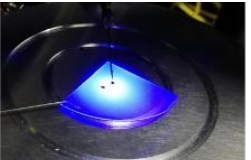

$\lambda_{\mathrm{p}}=445 \mathrm{~nm}$

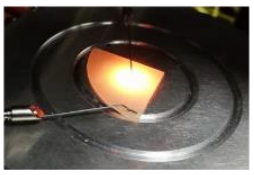

$\lambda_{\mathrm{p}}=610 \mathrm{~nm}$

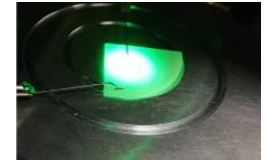

$\lambda_{\mathrm{p}}=525 \mathrm{~nm}$

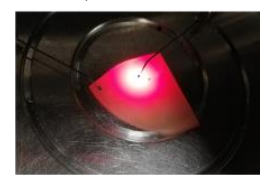

$\lambda_{\mathrm{p}}=660 \mathrm{~nm}$

Figure 12 InGaN LEDs with various In-contents $[5,8,30]$. The number represents the peak wavelength at $\mathrm{DC} 20 \mathrm{~mA}$, room temperature.

All the visible colors of InGaN LEDs have been realized, as shown in Figure 12. The conventional flow channel was used for the growth of the LED structures until $490 \mathrm{~nm}$ peak emissions, and the micro-flow channel was adopted for InGaN LEDs with peak wavelengths from $520 \mathrm{~nm}$ to $740 \mathrm{~nm}$. The potential of InGaN, which can cover the whole visible range, has been realized using the micro-flow channel. The 740-nm InGaN LEDs have high In-content of around $40 \%$, and the tail of the EL spectrum reaches IR of $900 \mathrm{~nm}$. The EL emission at $900 \mathrm{~nm}$ comes from the $\mathrm{In}_{0.5} \mathrm{Ga}_{0.5} \mathrm{~N}$ region. This result suggests that InGaN could replace arsenide and phosphide semiconductors.

\section{AIN-MOVPE}

MOVPE growth of AIN generally uses TMAI and $\mathrm{NH}_{3}$ as precursors and $\mathrm{H}_{2}$ as a carrier gas. The modeling of reaction pathways in the $\mathrm{TMAl} / \mathrm{NH}_{3} / \mathrm{H}_{2}$ system is shown in Figure 13 . The pathways include reactions obtained from the results of quantum chemical calculations and experiments $[9,21$, 33-36].

Figure 13 shows the schematic of representative reaction pathways of AIN growth. The thick red lines indicate the main pathways for AIN-MOVPE growth. The main AIN growth is the adsorption of Al$\mathrm{N}$ dimers on a surface at typical high temperatures, and the additional adsorption of $\mathrm{DMAINH}_{2}$, MMAINH at lower temperatures [9]. The reaction pathways can be explained by classifying them into several categories. One of the pathways is TMAl pyrolysis: TMAI $\rightarrow$ DMAI $\rightarrow$ MMAI $\rightarrow$ Al $[35,36]$. Their further reactions with $\mathrm{H}$ or $\mathrm{H}_{2}$ are the formation of $\mathrm{DMAlH}, \mathrm{MMAlH}_{2}, \mathrm{AlH}_{2}$, and $\mathrm{AlH}_{3}$ [37-39]. Adduct formation such as TMAl: $\mathrm{NH}_{3}$ and $\mathrm{H}_{3} \mathrm{~N}$ :TMAl: $\mathrm{NH}_{3}$ were considered [34]. By the $\mathrm{CH}_{4}$ elimination from those adducts, DMAINH$H_{2}$ was formed (TMAl: $\mathrm{NH}_{3} \rightarrow$ DMAINH$H_{2}+\mathrm{CH}_{4}$ ). The polymer formation of DMAINH$H_{2}$ molecules was also included (DMAINH $\left.{ }_{2} \rightarrow\left[\mathrm{DMAINH}_{2}\right]_{n}\right)$. Further pyrolysis of DMAINH $\left(\right.$ DMAINH ${ }_{2} \rightarrow$ MMAINH $\rightarrow$ Al-N) happens with further $\mathrm{CH}_{4}$ emissions. Also, their polymerizations happen in the gas phase, such as MMAINH $\rightarrow[\mathrm{MMAINH}]_{\mathrm{n}}$, and Al-N $\rightarrow[\mathrm{Al}-\mathrm{N}]_{\mathrm{n}}$. Those polymerizations presumably coincide with the nanoparticle generation phenomena during AIN-MOVPE [40]. The polymer formations are indispensable to simulate growth rates at higher pressures. Numerical AIN growth rates under MOVPE with different temperatures or different pressures exhibited good agreement with experimental values. Figures 14 (a) and (b) show the pressure dependences of numerical and experimental growth rate and their chemical species. The molecules are getting larger with pressure since pressure enhances molecular collisions, and resulting in polymerization. Each value of $\mathrm{n}$ in $[\mathrm{Al}-\mathrm{N}]_{\mathrm{n}}$ or $[\mathrm{MMAINH}]_{\mathrm{n}}$ increases with pressure. Therefore, Al atoms were consumed as polymers at higher pressures, resulting in a decrease in growth rate. 


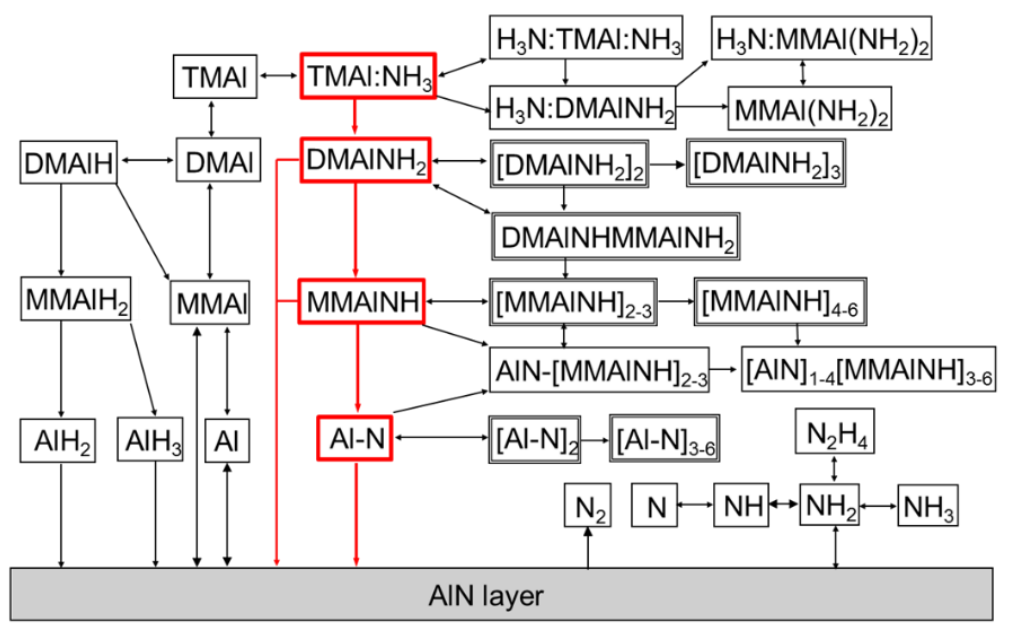

Figure 13 Schematic diagram of representative reaction pathways for the MOVPE growth of AIN from the TMAI/ $/ \mathrm{NH}_{3} / \mathrm{H}_{2}$ system [9]. The thick red frames and arrows indicate the main growth path of the TMAl: $\mathrm{NH}_{3}$ adduct pyrolysis. The second-thick red arrows from DMAINH ${ }_{2}$ and MMAINH show the substitutional growth paths at low temperatures.
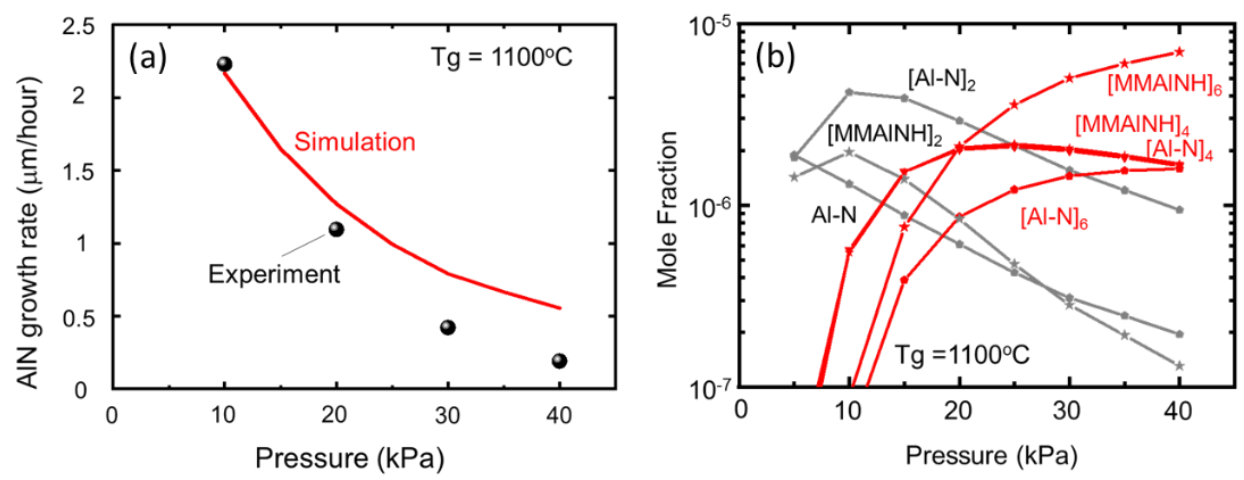

Figure 14 (a) Pressure dependence of AIN growth rates in simulation and experiment. (b) Concentrations of representative Al-containing molecules vs. pressure [9]. The concentrations are from the gas phase at $+0.1 \mathrm{~mm}$ above the substrate center. The concentrations of $\mathrm{DMAINH}_{2}$ and its polymers at $1100^{\circ} \mathrm{C}$ are far below this range.

It is scientifically-curious to compare the main growth pathways in AIN-, GaN-, and InN-MOVPEs. In the case of AIN growth, the growth pathway from the pyrolysis of TMAl: $\mathrm{NH}_{3}$ adducts is $100 \%$ in any growth conditions as far as the simultaneous precursor flow of $\mathrm{TMAl}$ and $\mathrm{NH}_{3}$. On the other hand, InN growth originates entirely from the combination of pyrolysis of precursors of TMIn and $\mathrm{NH}_{3}$ as shown in Figure 15. TMIn: $\mathrm{NH}_{3}$ adducts did not contribute to InN growth. GaN-MOVPE growth is between those. Atmospheric-pressure (100 kPa) MOVPE growth of GaN indicates that a 90\% pathway is the pyrolysis of TMGa: $\mathrm{NH}_{3}$ adducts, while the remaining $10 \%$ is the pyrolysis of the precursors. Lowpressure (10 $\mathrm{kPa}$ ) MOVPE shifts to the InN-MOVPE side and shows $60 \%$ of the adduct pyrolysis and $40 \%$ of the precursor pyrolysis. The contribution values of $90 \%$ and $60 \%$ for the adduct pyrolysis pathway in growth were confirmed by cutting each reaction pathways [41].

In those AIN-, GaN-, and InN-MOVPEs, each material has a typical V/III ratio in Table 1. Each V/III 
ratio originates from the growth mechanism, especially from the ratio of the adduct pyrolysis and the precursor pyrolysis. Because the TMAI: $\mathrm{NH}_{3}$ adduct pyrolysis is the main method of growth of AIN, Al$\mathrm{N}$ dimers are the main molecules for the growth. Al atoms and $\mathrm{N}$ atoms for AIN growth are supplied by the Al-N dimers at the same time. Therefore, the V/III ratio of AIN-MOVPE is not large compared to those of $\mathrm{GaN}$ and $\operatorname{InN}$, as shown in Table 1 . InN growth is based on the precursor pyrolysis. The InN semiconductor is easily decomposed and emits $\mathrm{N}_{2}$ molecules, so InN-MOVPE requests lowtemperature growth. The thermal decomposition of $\mathrm{NH}_{3}$ is not efficient. Therefore, the huge $\mathrm{V} / \mathrm{III}$ ratio is necessary to supply sufficient $\mathrm{NH}_{2}$ molecules on the surface for InN-MOVPE. As the MOVPE growth mechanism of $\mathrm{GaN}$ is characterized in between those of AIN and InN, the V/III ratio of GaN-MOVPE also exists in the middle of them. The different $\mathrm{V} / \mathrm{III}$ ratios in those nitride semiconductors presumably originate from the balance of those growth pathways. Also, growth pressure is related to polymer formation. AIN-MOVPE easily causes polymer formation, so the low pressures are preferable.

Concerning InGaN and AlGaN alloys, their growth mechanisms are the combination of binaries. The growth of InGaN is GaN plus InN growth. Chapter 4 (InN \& InGaN-MOVPE) did not consider any interaction between In- and Ga-containing molecules, but the In content and growth rate were successfully explained. Therefore, the InGaN growth mechanism is also the simple plus of GaN (Adduct pyrolysis + precursor pyrolysis) and InN (precursor pyrolysis). AIGaN-MOVPE will be described in the next chapter. However, the part of the AIGaN growth mechanism is the simple plus of AIN (Adduct pyrolysis) and GaN (Adduct pyrolysis + precursor pyrolysis). Its growth loss will be explained by considering polymerization in the next chapter.

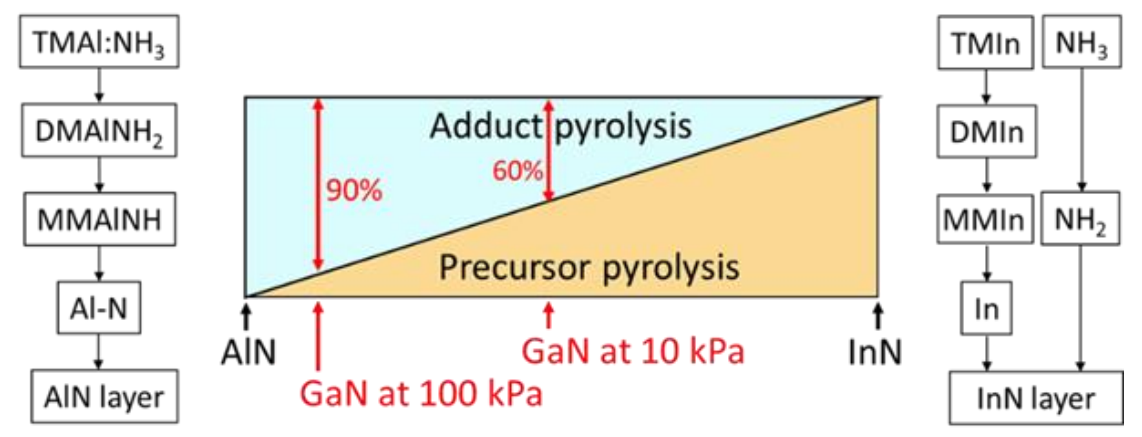

Figure 15 MOVPE growth mechanism of nitride semiconductors. The ratios of the adduct pyrolysis part and the precursor pyrolysis part in the MOVPE growth contribution of AIN, GaN, and InN. The case of AIN growth is $100 \%$ of the adduct pyrolysis. The case of $\operatorname{InN}$ is only the precursor pyrolysis. The case of $\mathrm{GaN}$ depends on its growth pressure. The adduct pyrolysis parts are $90 \%$ and $60 \%$ of the growth contribution in GaN MOVPE at $100 \mathrm{kPa}$ and $10 \mathrm{kPa}$, respectively. AlGaN and InGaN growths are the simple pluses of AIN and GaN or of InN and GaN, respectively.

Table 1 Typical V/III ratios and their pressure in the MOVPE growth of AIN, GaN, and $\ln N$.

\begin{tabular}{|c|c|c|}
\hline & $\begin{array}{c}\text { Typical order of V/III ratio } \\
\text { Growth pressure }\end{array}$ & Reference \\
\hline AIN & $\begin{array}{r}10^{2} \\
13 \mathrm{kPa}\end{array}$ & {$[42]$} \\
\hline GaN & $\begin{array}{r}10^{3} \\
100 \mathrm{kPa}\end{array}$ & {$[4]$} \\
\hline $\operatorname{InN}$ & $\begin{array}{r}10^{5} \\
100 \mathrm{kPa}\end{array}$ & {$[43]$} \\
\hline
\end{tabular}




\section{AIGaN-MOVPE and polymer formation}

The bandgap of the $A l_{x} \mathrm{Ga}_{1-\mathrm{x}} \mathrm{N}$ system covers $3.42 \mathrm{eV}$ to $6.04 \mathrm{eV}[27,44]$. AlGaN materials are useful for UV-LEDs, UV-laser diodes, and electronic devices. The AIN growth rate is linear to the flow rate of TMAI [45]. However, the AlGaN growth rate is strange. Through the addition of TMAl to the constant flow of TMGa to grow AlGaN, its growth rate decreases with the increment of the TMAl flow rate [45-47]. That decline in the AIGaN growth rate indicates the existence of additional polymerizations among Al- and Ga-containing molecules in a TMAI/TMGa/NH $/ \mathrm{NH}_{3} / \mathrm{H}_{2}$ system, and that polymer formation prevents the AIGaN growth. The key issue in AIGaN-MOVPE is to understand such Al- and Ga-containing polymers.

Figure 16 shows the cross-sectional view of a single-wafer horizontal MOVPE reactor for the experiments, and its 2-dimensional model for simulation. Precursors were TMGa, TMAl, and $\mathrm{NH}_{3}$. The carrier gas was hydrogen. Substrates were 2-inch c-plane sapphire wafers. The typical growth temperature was $1025^{\circ} \mathrm{C}$. The values of growth temperature and growth rate hereafter are those at the center of a substrate. The gas-flow conditions of the experiments for pressure and temperature dependences were $\mathrm{TMAl}=47.3 \mu \mathrm{mol} / \mathrm{min}, \mathrm{TMGa}=52.7 \mu \mathrm{mol} / \mathrm{min}, \mathrm{NH}_{3}=4.5 \mathrm{slm}$, and $\mathrm{H}_{2}=4.6 \mathrm{slm}$. The $\mathrm{TMAl} /(\mathrm{TMAl}+\mathrm{TMGa}$ ) ratio was varied from 0 to 1 by changing TMAl and TMGa from $0 \mu \mathrm{mol} / \mathrm{min}$ to $100 \mu \mathrm{mol} / \mathrm{min}$ under a constant flow of TMAl+TMGa=100 $\mu \mathrm{mol} / \mathrm{min}$.

Figure 16 (a) exhibits the temperature distribution simulated under the growth conditions at $1025^{\circ} \mathrm{C}$ and $40 \mathrm{kPa}$ with $\mathrm{TMGa}, \mathrm{TMAl}$, and $\mathrm{NH}_{3}$. The outside of the flow channel in both the simulation and the experiment was filled with nitrogen gas. The following two points are important to obtain precise temperature distribution. The first point is the consideration of thermal radiation and the absorption of materials in the reactor, as the growth temperature of nitride MOVPE is very high. The thermal radiation and the absorption spectra from the quartz parts were measured experimentally at elevated temperatures [11]. The second point is the imperfect thermal contacts among the sapphire substrate, the quartz tray, and the susceptor by considering some spaces. These spacings would be filled with mainly $\mathrm{H}_{2}$ gas that was used as the carrier gas during growth. The hydrogen gas in the space acts as a thermal conductor. Furthermore, thermal radiation and absorption on both sides were considered in the simulations.

The simple combination of GaN- and AIN-MOVPE reaction pathways in Figures 3 and 13 is useful for finding the reactive molecules forming Al- and Ga-containing polymers in AIGaN MOVPE. The simple combination neglects the formation of Al- and Ga-containing polymers. Using this simple combination, Figures 16 (b) and (c) exhibit the spatial distributions of the reactive molecules such as MMGaNH, Ga-N, MMAINH, and Al-N in a TMAI/TMGa/NH $/ \mathrm{NH}_{2}$ system. It should be noted that the spatial distribution of each reactive molecule has a similar shape with a certain range in the temperature distribution in Figure 16 (a). MMGaNH molecules exist only at a temperature of around $350^{\circ} \mathrm{C}$, then decompose into $\mathrm{Ga}-\mathrm{N}$ molecules with $\mathrm{CH}_{4}$ emissions at around $450^{\circ} \mathrm{C}$ [7]. Ga-N molecules are reactive and their distribution is spatially wide. In the case of the $T M A I / \mathrm{NH}_{3} / \mathrm{H}_{2}$ system, MMAINH and $\mathrm{Al}-\mathrm{N}$ molecules are created at around $900^{\circ} \mathrm{C}$ and $1000^{\circ} \mathrm{C}$, respectively. Therefore, those molecules exist widely around the substrate.

Polymerization occurs when reactive molecules exist in the same space. The spatial distributions of Ga-N, MMAINH, and Al-N overlap each other in some regions. Therefore, the possible combinations of Al- and Ga-containing polymers will be mainly three kinds: $[\mathrm{MMAINH}]_{n}-[\mathrm{Ga}-\mathrm{N}]_{\mathrm{m}},[\mathrm{MMAINH}]_{\mathrm{n}}-[\mathrm{Ga}-$ 
$\mathrm{N}]_{\mathrm{m}}-[\mathrm{Al}-\mathrm{N}]_{\mathrm{I}}$, and $[\mathrm{Al}-\mathrm{N}]_{\mathrm{n}}-[\mathrm{Ga}-\mathrm{N}]_{\mathrm{m}}$. The molecular parameters of those polymers were also considered by using the nitride-MOVPE database [12]. Figure 17 shows the schematic reaction pathways for AlGaN-MOVPE. AIGaN growth has two paths of AIN and GaN growth. The reactive molecules were generated from the decomposition of adducts in the high-temperature regions. Also, the reactive molecules formed several kinds of polymers, such as $\left[\mathrm{DMAINH}_{2}\right]_{n},[\mathrm{MMAINH}]_{n},[\mathrm{Al}-\mathrm{N}]_{n}$, their Garelated ones, and those Al- and Ga-containing polymers.

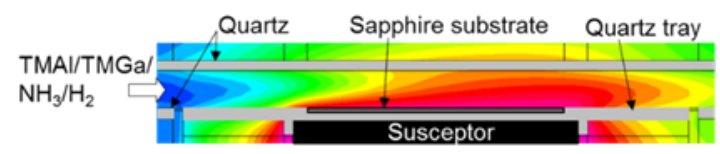

(a) Temperature distribution (Max: $1025^{\circ} \mathrm{C}$, Min: $27^{\circ} \mathrm{C}$ )

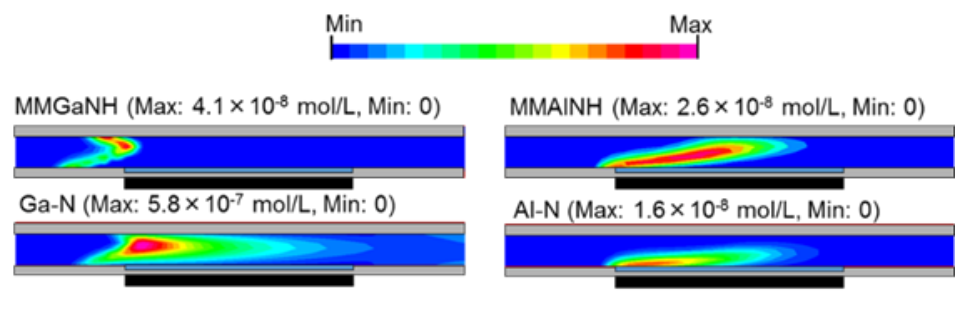

(b) $\mathrm{GaN}$ reactive molecules

(c) AIN reactive molecules

Figure 16 (a) Temperature distribution of the 2D reactor model [10]. The substrate temperature and reactor pressure are $1025^{\circ} \mathrm{C}$ and $40 \mathrm{kPa}$, respectively. (b) Spatial distributions of reactive molecules related to the GaN growth part, and (c) those in the AIN growth part [10]. The reactions among Al- and Ga-containing molecules were neglected.

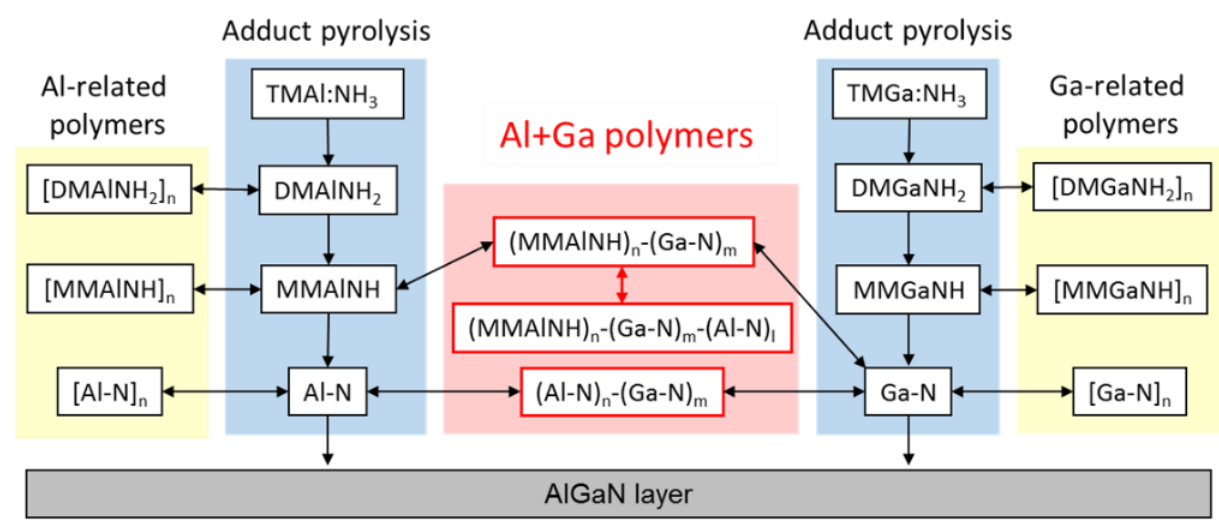

Figure 17 Schematic representative reaction pathways in the TMAI/TMGa/NH $/ \mathrm{N}_{2}$ system [10]. The simplified reactions for AIN growth and Al-containing polymers are shown on the left side. Those for the GaN part are on the right side. The middle part indicates the polymers between Al- and Ga-containing molecules.

The pressure of a growth reactor is an influential parameter for AIGaN-MOVPE. The experimental results exhibited strong pressure dependences of growth rate and $\mathrm{Al}$ content in Figure 18 . The thin black line is the simulation without the polymerization among Al- and Ga-containing molecules. In this case, the pressure dependence of the calculated growth rate is far from the experimental values, especially at higher pressures. Al-containing molecules easily form polymers with pressure [9]. 
Therefore, at higher pressures, the AlGaN growth rate approaches the GaN growth rate, and the Al content approaches zero. Using the polymerization model in Figure 17, the calculated AIGaN growth rate and its Al content showed good agreement with those of the experiments from low pressure to atmospheric pressure. The result supports the polymer formation modeling of Al- and Ga-containing polymers.
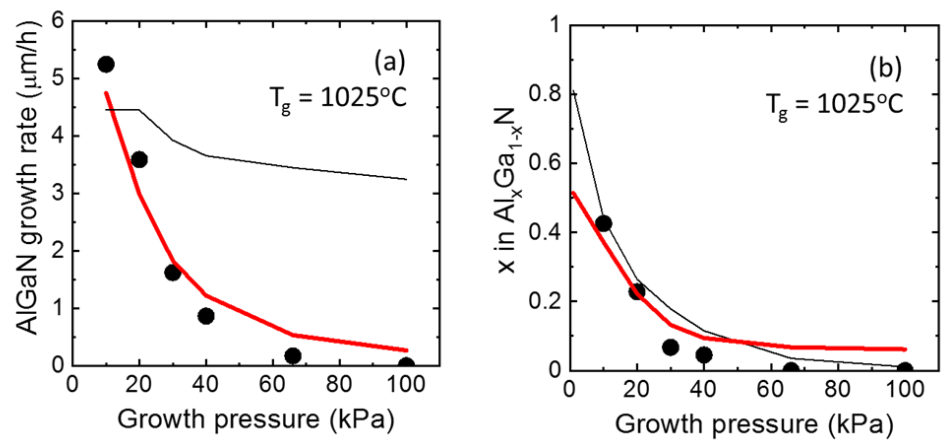

Figure 18 Pressure dependences of growth rate and Al content in AIGaN [10]. The thick red and thinner black curves are simulations with or without the formation of Al- and Ga-containing polymers, respectively. The solid circles are experimental values.

The TMAl/(TMAl+TMGa) ratio at the gas inlet is also an important parameter to control the Al content in AlGaN. Figure 19 is the comparison of the TMAI/(TMAl+TMGa) ratio dependences of AlGaNMOVPE under $10 \mathrm{kPa}$ and $40 \mathrm{kPa}$. The simulated and experimental features are in good agreement qualitatively and quantitatively for both values of pressure. These results also support the polymerization model among Al- and Ga-containing molecules. The ratio dependences of growth rate and Al content at low-pressure show almost linear characteristics, which means that, in this case, the polymer formation would be suppressed. Previous work also reported a linear dependence of growth rate and $\mathrm{Al}$ content on the TMAI/(TMAl+TMGa) ratio experimentally and numerically only at low pressure [48]. At a higher pressure of $40 \mathrm{kPa}$, the ratio dependence became non-linear. The simulation can explain that the non-linearity arises from the enhanced polymerization at around a $\mathrm{TMAl} /(\mathrm{TMAl}+\mathrm{TMGa}$ ) ratio of 0.5 because the loss of the precursors of TMAl and TMGa is high at such a ratio.
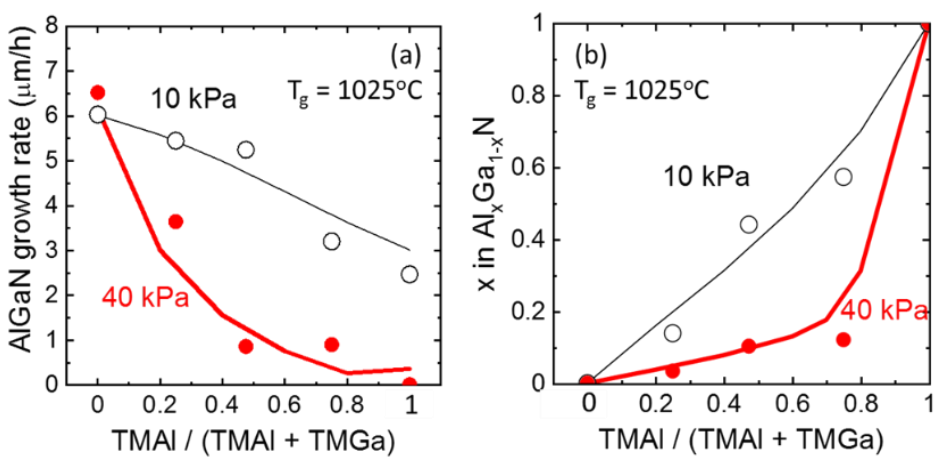

Figure 19 Ratio TMAI/(TMAl+TMGa) dependences of growth rate and Al content in AIGaN [10]. The open black and solid red circles are experimental values at growth pressures of $10 \mathrm{kPa}$ and $40 \mathrm{kPa}$, respectively. The curves are simulations. 

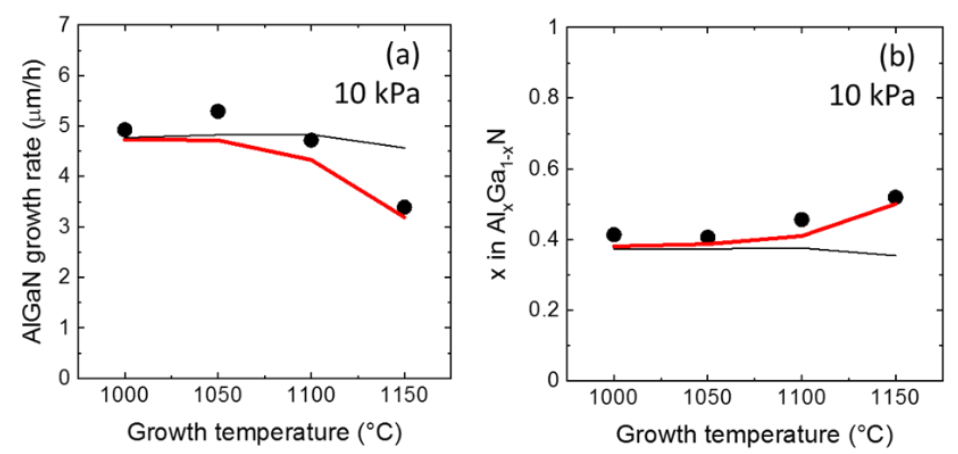

Figure 20 Temperature dependences of growth rate and Al content in AlGaN [10]. The thick red and thinner black curves are the simulation results from models with or without the GaN decomposition, respectively. The solid circles are experimental values.

In the experiment, the growth rate decreased at high temperatures, but the Al content increased. The AIGaN-MOVPE simulations with and without GaN decomposition exhibited similar values at lower temperatures but different values at higher temperatures as shown in Figure 20. Decomposition of $\mathrm{GaN}$ crystal causes the emission of $\mathrm{Ga}$ atoms, $\mathrm{MMGa}, \mathrm{N}_{2}$, and $\mathrm{NH}_{2}$ molecules. Those decomposition reactions are included in the reaction pathways for GaN-MOVPE from the TMGa/ $/ \mathrm{NH}_{3} / \mathrm{H}_{2}$ system in Figure 3. GaN decomposition became remarkable from $1100^{\circ} \mathrm{C}$ and more. The simulations considering the GaN decomposition were in excellent agreement with the experiments at high temperatures.

\section{Summary}

MOVPE growth of nitride semiconductors is unique because GaN, InGaN, AIN, and AIGaN have different optimal growth conditions. The MOVPE growth mechanisms of those nitride semiconductors are important to understand such unique growth conditions. It was found that there are two growth pathways of the adduct pyrolysis and the precursor pyrolysis. The AIN growth originated $100 \%$ from the pyrolysis of TMAl: $\mathrm{NH}_{3}$ adducts. In contrast, the InN growth is $100 \%$ from the pyrolysis of precursors. The GaN growth has both pyrolysis processes. The consideration of the polymer formation was crucial to achieving the qualitative and quantitative agreements of growth rate and alloy composition among experiments and the simulation. The Al-containing molecules are very reactive and easily formed polymers compared to other Ga- and In-containing molecules. Therefore, AlGaN growth prefers lowpressure MOVPE to suppress the polymer formation. Also, the sublimation of InN or GaN influenced growth rate and alloy composition, suggesting their growth temperatures.

\section{Outlook}

The recent MOVPE systems for production are becoming larger, consume huge amounts of precursors, and every growth costs very much. The growth image obtained from the abovementioned 
results could help to save time and costs in realizing the optimized MOVPE growth of nitride semiconductors.

On the other hand, there are different types of nitride MOVPE methods. The precursor flow is not only horizontal but also vertical. The precursors were well-mixed or separated for feeding the substrates. The abovementioned phenomena will be the same as both horizontal and vertical MOVPE reactors since each isothermal region determines each chemical reaction. The direction of thermal convection will be different, so the setting of gravity in the CFD code is mandatory.

However, the combination of the non-mixture precursors' feeding and the high-speed rotation of substrates requires the time-dependent simulation. The non-mixture feeding is to separate the group-III metal-organic gas flow and the ammonia flow. These flows close to the surface with thinner flow layers due to the substrate rotation. Therefore, the growth surface will have high and low V/III ratio modes alternatively. Such flow modulation in MOVPE presumably suppresses the formation of adducts and their polymerization [49]. Therefore, the current reaction pathways for the MOVPE of GaN, InGaN, AIN, and AIGaN are valid for calculating the flow modulation MOVPE because the growth paths will be selected automatically by the precursors' feeding methods.

Besides, MOVPE growth conditions can change the surface migration of atoms, resulting in nanostructures. The current simulation is not enough to calculate surface morphology. Such simulation needs values of the adsorption and decomposition energies depending on the surface morphology.

\section{Appendix}

Table 2 Typical values in experimental and simulational growth conditions used in this article.

\begin{tabular}{|c|c|c|c|c|c|}
\hline & AIN & AlGaN & GaN & InGaN & $\ln N$ \\
\hline Temperature $\left[{ }^{\circ} \mathrm{C}\right]$ & 1100 & $\begin{array}{c}1025 \\
(1000-1150)\end{array}$ & $\begin{array}{c}1030 \\
(350-1130)\end{array}$ & $\begin{array}{c}763 \\
(671-855)\end{array}$ & 500 \\
\hline Pressure $[\mathrm{kPa}]$ & $10(10-40)$ & $10(10-100)$ & 100 & 100 & 100 \\
\hline $\begin{array}{c}\text { Initial V/III ratio } \\
\mathrm{MO}[\mu \mathrm{mol} / \mathrm{min}] \\
\mathrm{NH}_{3}(\mathrm{slm}]\end{array}$ & $\begin{array}{c}4300 \\
\text { TMAl } 47 \\
\mathrm{NH}_{3} 4.5\end{array}$ & $\begin{array}{c}2000 \\
\text { TMAI } 47.3(0-100) \\
\text { TMGa } 52.7(0-100) \\
\mathrm{NH}_{3} 4.5\end{array}$ & $\begin{array}{c}1500 \\
\mathrm{TMGa}_{30} \\
\mathrm{NH}_{3} 1.0\end{array}$ & $\begin{array}{c}6300 \\
\text { TMGa } 11.3 \\
\text { TMIn } 20.5 \\
\mathrm{NH}_{3} 4.5\end{array}$ & $\begin{array}{c}6.6 \times 10^{5} \\
\mathrm{TMIn} 1.0 \\
\mathrm{NH}_{3} 15\end{array}$ \\
\hline $\begin{array}{l}\text { Growth rate }[\mu \mathrm{m} / \mathrm{h}] \\
\text { Carrier gas }\end{array}$ & $\begin{array}{l}2.2 \\
\mathrm{H}_{2}\end{array}$ & $\begin{array}{c}5.25 \\
\mathrm{H}_{2}\end{array}$ & $\begin{array}{c}1.85 \\
\mathrm{H}_{2}\end{array}$ & $\begin{array}{l}0.3 \\
\mathrm{~N}_{2}\end{array}$ & $\begin{array}{c}<0.025 \\
\mathrm{~N}_{2}\end{array}$ \\
\hline $\begin{array}{l}\text { Related figures } \\
\text { References }\end{array}$ & $\begin{array}{l}14 \\
{[9]}\end{array}$ & $\begin{array}{c}18,19,20 \\
{[10]}\end{array}$ & $\begin{array}{c}6 \\
{[7]}\end{array}$ & $\begin{array}{c}9 \\
{[8]}\end{array}$ & $\begin{array}{c}15 \\
{[43]}\end{array}$ \\
\hline
\end{tabular}

The values in the brackets are used as parameters for temperature, pressure, and precursors' ratio dependences of growth. The growth rates are the values under the typical growth conditions.

\section{References}

[1] M. Ishikawa, Y. Ohba, H. Sugawara, M. Yamamoto, and T. Nakanisi, Appl. Phys. Lett. 48, 207 (1986); https://doi.org/10.1063/1.96796

[2] M. Ikeda, Y. Mori, M. Takiguchi, K. Kaneko, and N. Watanabe, Appl. Phys. Lett. 45, 661 (1984); https://doi.org/10.1063/1.95363 
[3] H.F.J. van't Blik, J.H.J.M. Boerrigter-Lammers, A. Valster, and Gerard A. Acket, Proc. SPIE vol. 1025, Semiconductor Lasers, (1989); https://doi.org/10.1117/12.950210

[4] Shuji Nakamura, Takashi Mukai, and Masayuki Senoh, Appl. Phys. Lett. 64, 1687 (1994); https://doi.org/10.1063/1.111832

[5] Daisuke lida, Zhe Zhuang, Pavel Kirilenko, Martin Velazquez-Rizo, Mohammed A. Najmi, and Kazuhiro Ohkawa, Appl. Phys. Lett. 116, 162101 (2020); https://doi.org/10.1063/1.5142538

[6] S. Nakamura, and G. Fasol, in Chapters 8-11 of "The Blue Laser Diode" (Springer, Heidelberg, 1997).

[7] Akira Hirako, Kazuhide Kusakabe, and Kazuhiro Ohkawa, Jpn. J. Appl. Phys. 44, 874 (2005); https://doi.org/10.1143/JJAP.44.874

[8] Kazuhiro Ohkawa, Fumitaka Ichinohe, Tomomasa Watanabe, Kenichi Nakamura, and Daisuke lida, J. Cryst. Growth 512, 69-73 (2019); https://doi.org/10.1016/j.jcrysgro.2019.02.018

[9] T. Uchida, K. Kusakabe, and K. Ohkawa, J. Cryst. Growth 304, 133 (2007);

https://doi.org/10.1016/j.jcrysgro.2007.01.022

[10] Kazuhiro Ohkawa, Kenichi Nakamura, Akira Hirako, and Daisuke lida, J. Cryst. Growth 516, $17-$ 20 (2019); https://doi.org/10.1016/j.jcrysgro.2019.03.023

[11] A. Hirako, and K. Ohkawa, J. Cryst. Growth 276, 57 (2005);

https://doi.org/10.1016/j.jcrysgro.2004.11.373

[12] http://www.wavefront.co.jp/CAE/MOVPE-database

[13] S. Mazumder, and D. Sengupta, J. Cryst. Growth 261, 165 (2004);

https://doi.org/10.1016/j.jcrysgro.2003.11.009

[14] S. Mazumder and S. A. Lowry, J. Cryst. Growth 224, 165 (2001); https://doi.org/10.1016/S00220248(01)00813-2

[15] A. Thon and T. F. Kuech, Appl. Phys. Lett. 69, 55 (1996); https://doi.org/10.1063/1.118117

[16] T. J. Mountziaris and K. F. Jensen, J. Electrochem. Soc. 138, 2426 (1991).

[17] K. Sekiguchi, H. Shirakawa, K. Chokawa, M. Araidai, Y. Kangawa, K. Kakimoto, K. Shiraishi, Jpn. J. Appl. Phys. 57, 04FJ03 (2018); https://doi.org/10.7567/JJAP.57.04FJ03

[18] Naoki Kobayashi, Toshiki Makimoto, Yoshiharu Yamauchi, and Yoshiji Horikoshi, J. Appl. Phys. 66, 640 (1989); https://doi.org/10.1063/1.343531

[19] D. Sengupta, J. Phys. Chem. B 107, 291 (2003); https://doi.org/10.1021/jp021721i

[20] J. Sun, J. M. Redwing, and T. F. Kuech, J. Electronic Materials 29, 2 (2000).

[21] Yuji Ikeda, Norifumi Ohmori, Noriaki Maida, Masato Senami, and Akitomo Tachibana, Jpn. J. Appl. Phys. 50, 125601 (2011); https://doi.org/10.1143/JJAP.50.125601

[22] T.G. Mihopoulos, Ph.D. Thesis "Reaction and transport processes in MOCVD selective and group III-Nitride growth", Massachusetts Institute of Technology, 1999.

[23] A. Y. Timoshkin, H. F. Bettinger, and H. F. Schaefer, J. Phys. Chem. A 105, 3240 (2001);

https://doi.org/10.1021/jp002379h 
[24] A. Hirako, S. Koiso, K. Ohkawa, phys. Stat. solidi (a) 203, 1716 (2006);

https://doi.org/10.1002/pssa.200565211

[25] A. Hirako, K. Ohkawa, J. Cryst. Growth 289, 428 (2006);

https://doi.org/10.1016/j.jcrysgro.2005.11.125

[26] T. Araki, Y. Saito, T. Yamaguchi, M. Kurouchi, Y. Nanishi, H. Naoi, J. Vac. Sci. Technol. B 22, 2139 (2004); https://doi.org/10.1116/1.1771682

[27] D. Brunner, H. Angerer, E. Bustarret, F. Freudenberg, R. Höpler, R. Dimitrov, O. Ambacher, and M. Stutzmann, J. Appl. Phys. 82, 5090 (1997); https://doi.org/10.1063/1.366309

[28] S. Nakamura, M. Senoh, N. Iwasa, and S. Nagahama, Appl. Phys. Lett. 67, 1868 (1995);

https://doi.org/10.1063/1.114359

[29] Zhe Zhuang, Daisuke lida, and Kazuhiro Ohkawa, Appl. Phys. Lett. 116, 173501 (2020); https://doi.org/10.1063/5.0006910

[30] K. Ohkawa, T. Watanabe, M. Sakamoto, A. Hirako, and M. Deura, J. Cryst. Growth 343, 13 (2012); https://doi.org/10.1016/j.jcrysgro.2019.02.018

[31] Y. Yamashita, H. Tamura, N. Horio, H. Sato, K. Taniguchi, T. Chinone, S. Omori, and C. Funaoka, Jpn. J. Appl. Phys. 42, 4197 (2003).

[32] P.T. Barletta, E.A. Berkman, B.F. Moody, N.A. El-Masry, A.M. Emara, M.J. Reed, and S.M. Bedair, Appl. Phys. Lett. 90, 151109 (2007); https://doi.org/10.1063/1.2721133

[33] T. G. Mihopoulos, V. Gupta, and K. F. Jensen, J. Cryst. Growth 195, 733 (1998);

https://doi.org/10.1016/S0022-0248(98)00649-6

[34] K. Nakamura, O. Makino, A. Tachibana, and K. Matsumoto, J. Organometallic Chemistry 611, 514 (2000); https://doi.org/10.1016/S0022-328X(00)00403-4

[35] Ö. Danielsson and E. Janzén, J. Cryst. Growth 253, 26 (2003); https://doi.org/10.1016/\$00220248(03)00971-0

[36] C. Cavallotti, I. Lengyel, M. Nemirovskaya, and K. F. Jensen, J. Cryst. Growth 268, 76 (2004); https://doi.org/10.1016/j.jcrysgro.2004.04.033

[37] Y. S. Hiraoka and M. Mashita, Jpn. J. Appl. Phys. 31, 3703 (1992).

[38] Y. S. Hiraoka, M. Mashita, T. Tada and R. Yoshimura, J. Cryst. Growth 128, 494 (1993).

[39] Y. S. Hiraoka and M. Mashita, J. Cryst. Growth 145, 473 (1994).

[40] J. R. Creighton, G. T. Wang, W. G. Breiland and M. E. Coltrin, J. Cryst. Growth 261, 204 (2004); https://doi.org/10.1016/j.jcrysgro.2003.11.074

[41] F. Hoshino, M. Deura, K. Ohkawa, Abstract in 2012 Spring Meeting of Applied Physic, March 1518, 2012, Tokyo, Japan, 16p-F12-15.

[42] Kenjiro Uesugi, Yusuke Hayashi, Kanako Shojiki, and Hideto Miyake, Appl. Phys. Express 12, 065501 (2019); https://doi.org/10.7567/1882-0786/ab1ab8

[43] T. Matsuoka, H. Okamoto, and M. Nakao, Phys. Stat. Sol. c 0, 2806 (2003);

https://doi.org/10.1002/pssc.200303301 
[44] S. F. Chichibu, K. Hazu, Y. Ishikawa, M. Tashiro, T. Ohtomo, K. Furusawa, A. Uedono, S. Mita, J. Xie, R. Collazo, and Z. Sitar, Appl. Phys. Lett. 103, 142103 (2013); https://doi.org/10.1063/1.4823826

[45] D. G. Zhao, Z. S. Liu, J. J. Zhu, S. M. Zhang, D. S. Jiang, H. Yang, J. W. Liang, X. Y. Li, and H. M. Gong, Appl. Surf. Sci. 253, 2452 (2006); https://doi.org/10.1016/j.apsusc.2006.04.062

[46] J. Han, J. J. Figiel, M. H. Crawford, M. A. Banas, M. E. Bartram, R. M. Biefeld, Y. K. Song, and A. V. Nurmikko, J. Cryst. Growth 195, 291 (1998).

[47] K. Matsumoto, and A. Tachibana, J. Cryst. Growth 272, 360 (2004);

https://doi.org/10.1016/j.jcrysgro.2004.08.115

[48] J. Stellmach, M. Pristovsek, O. Savas, J. Schlegel, E. V. Yakovlev, and M. Kneissl, J. Cryst. Growth 315, 229 (2011); https://doi.org/10.1016/j.jcrysgro.2010.06.036

[49] K. Nakamura, A. Hirako, K. Ohkawa, Phys. Status Solidi C 7, 2268 (2010);

https://doi.org/10.1002/pssc.200983580 